\title{
Isolation of Novel Probiotic Lactobacillus and Enterococcus Strains From Human Salivary and Fecal Sources
}

\author{
Homa Bazireh ${ }^{1}$, Parvin Shariati ${ }^{*}$, Sadegh Azimzadeh Jamalkandi , Ali Ahmadi ${ }^{3}$ and \\ Mohammad Ali Boroumand4
}

${ }^{1}$ Department of Bioprocess Engineering, Institute of Industrial and Environmental Biotechnology, National Institute of Genetic Engineering and Biotechnology, Tehran, Iran, ${ }^{2}$ Chemical Injuries Research Center, Systems Biology and Poisonings Institute, Baqiyatallah University of Medical Sciences, Tehran, Iran, ${ }^{3}$ Molecular Biology Research Center, Systems Biology and Poisonings Institute, Baqiyatallah University of Medical Sciences, Tehran, Iran, ${ }^{4}$ Department of Pathology and Laboratory Medicine, Tehran Heart Center, Tehran University of Medical Sciences, Tehran, Iran

OPEN ACCESS

Edited by:

Katia Sivieri,

São Paulo State University, Brazil

Reviewed by:

Yousef Nami,

Agricultural Biotechnology Research Institute of Iran, Iran

Adriane Antunes,

State University of Campinas, Brazil

*Correspondence:

Parvin Shariati

shariati@nigeb.ac.ir

Specialty section:

This article was submitted to

Food Microbiology,

a section of the journal

Frontiers in Microbiology

Received: 26 August 2020 Accepted: 11 November 2020 Published: 04 December 2020

Citation:

Bazireh H, Shariati $P$, Azimzadeh Jamalkandi S, Ahmadi A and Boroumand MA (2020) Isolation

of Novel Probiotic Lactobacillus and Enterococcus Strains From Human Salivary and Fecal Sources. Front. Microbiol. 11:597946. doi: 10.3389/fmicb.2020.597946
Probiotics are non-pathogenic microorganisms that can interact with the gastrointestinal microbiota. They have numerous beneficial health effects that include enhancement of the host immune response, antiallergic, antimicrobial, anti-cancer, and anti-inflammatory properties. Probiotics are capable of restoring the impaired microbiome of a dysbiotic gut. They can be isolated from different environments. However, it is frequently suggested that probiotics for human use should come from human sources. The objective of this study was to isolate and characterize novel probiotic strains from the saliva and feces of healthy human individuals. To meet the criteria for probiotic attributes, the isolates were subjected to numerous standard morphological and biochemical tests. These tests included Gram staining, catalase tests, antibiotic susceptibility testing, hemolytic and antagonistic evaluation, tolerance tests involving temperature, $\mathrm{NaCl}$ levels, $\mathrm{pH}$ and bile salts, adherence ability assays, and genotypic characterization involving 16S rRNA gene sequencing. From 26 saliva and 11 stool samples, 185 microbial strains were isolated. Based on morphological and biochemical characteristics, 14 potential probiotic candidates were selected and identified genotypically. The new strains belonged to Lactobacillus fermentum, Enterococcus faecium, and Enterococcus hire. The selected strains were non-hemolytic, showed high tolerance to low pH and bile salts, and strong adherence abilities. Furthermore, the strains displayed a wide range of antimicrobial activities, particularly against antibioticresistant pathogens such as methicillin resistant Staphylococcus aureus (MRSA). Moreover, five of the selected isolates demonstrated antiproliferative features against human colon cancer cell line (Caco-2). The results of this investigation confirm the diversity of microbial populations in the human gut and saliva, and since these strains are of human origin, they will highly likely display maximal activities in food and drugs set for human use. Hence, the new strains of this study require additional in vivo experiments to assess their health-promoting effects.

Keywords: probiotics, saliva, feces, Lactobacillus, Enterococcus, microbiome, lactic acid bacteria 


\section{INTRODUCTION}

Probiotics are live microorganisms that can confer health benefits to the host when consumed in adequate amounts FAO/WHO (2002). In fact, probiotics have recently been developed that can balance and restore the human gut microbiome inflicted with dysbiosis (Kumar et al., 2020). Many probiotics are lactic acidproducing bacteria $(\mathrm{LAB})$ that are Gram-positive and catalasenegative. The two most common genera of probiotics are Lactobacillus and Bifidobacterium, which have been shown to have beneficial roles in human health.

The use of probiotics not just as supplements but as actual treatment strategies for various diseases has now become more prevalent and the current focus of attention in the scientific and medical communities. The multidimensional effects of probiotics are currently being evaluated in many fields of medicine that include infectious diseases (Anwar et al., 2020; d'Ettorre et al., 2020; Silva et al., 2020; Tan et al., 2020), the immune system (Gill et al., 2000; Dargahi et al., 2020), chronic diseases such as cancer (Haghshenas et al., 2014; Nami et al., 2015), cardiovascular (Ettinger et al., 2014; Gómez-Guzmán et al., 2015; Daliri et al., 2017), neurodegenerative (Westfall et al., 2017), inflammatory diseases (Plaza-Díaz et al., 2017), and diabetes (Kocsis et al., 2020).

Accordingly, this has culminated in the search for new bacterial strains with numerous inherent attributes that can be of potential use in the treatment of many ailments and disorders. For example, the localized use of the probiotic Lactobacillus plantarum ATCC 10241 strain in a burn model was found to interfere with Pseudomonas aeruginosa, stimulating phagocytosis of this pathogen by tissue phagocytes, decreasing apoptosis, and thereby improving tissue repair (Valdéz et al., 2005). In recent years with the emergence of antibiotic resistance, a lot of emphasis has been placed on investigating probiotics and their products as alternatives to antibiotics. The antagonistic activity of probiotics against pathogens is brought about by a series of mechanisms that include, competitive exclusion of pathogens, boosting the function of the intestinal barrier, and producing effective antimicrobial compounds such as peptides (Fijan, 2016; Besser et al., 2019). Hence, numerous Lactobacillus strains have been found to inhibit the growth of many different types of multi-drug resistant bacterial pathogens, such as MRSA (methicillin resistant Staphylococcus aureus), Streptococcus mutans, Escherichia coli, P. aeruginosa, Klebsiella pneumoniae, Shigella spp. and Clostridium difficile (McFarland, 2015; Kumar et al., 2016; Kang et al., 2017; Chen et al., 2019; Nami et al., 2019b).

In another study, the cholesterol removal capacity of L. plantarum YS5 in vitro was shown to reduce cholesterol levels by $84 \%$. Moreover, probiotic supplementation was found to decrease serum total cholesterol, low density lipoprotein cholesterol, and triglyceride levels in male Wistar rats (Nami et al., 2019a). In other research involving colon cancer, the administration of Lactobacillus acidophilus ATCC 314 and Lactobacillus fermentum NCIMB 5221 in the murine colon cancer model was found to reduce or stop the growth of tumors, by stimulating an antitumor immune response (Kahouli et al., 2017). Many studies have shown that certain specific probiotics exhibit anticarcinogenic activities and contribute to the prevention of colon cancer through host-dependent mechanisms. One such mechanism involves the production of metabolites such as SCFAs, acetate, propionate and butyrate by a number of probiotic Lactobacillus, Bifidobacterium, and Streptococcus strains, showing positive effects on immune and epithelial cells (Ganapathy et al., 2013; Singh et al., 2014; Gao et al., 2017; Drago, 2019).

Probiotics can be found in many environments such as dairy products, fermented, food and humans. However, the use of probiotics of human origin for use in humans is frequently proposed (Sanders, 2008; Kumar et al., 2020).

The aim of this study is to identify novel indigenous bacterial strains from healthy human individuals that can be used as potential probiotics for the treatment and prevention of various human ailments. In order to be recognized as potential probiotics, bacterial strains that are isolated from various sources must meet specific criteria. For this purpose, a series of standard tests are usually carried out to identify and characterize potential probiotic strains. These tests include evaluating the ability to survive under harsh conditions, e.g., low $\mathrm{pH}$, the presence of antibacterial activity, ability to adhere to epithelial cells, demonstrating non-hemolytic activity, and lacking antibiotic resistance genes.

\section{MATERIALS AND METHODS}

\section{Materials, Reagents and Strains}

Standard strains were purchased from the Iranian Research Organization for Science and Technology (IROST), and culture media were obtained from Ibresco, Zist Kavosh Iranian Co, Iran. All antibiogram disks were provided by Padtan Teb Co. (Iran) including gentamycin, cefixime, penicillin, chloramphenicol, streptomycin, erythromycin, ampicillin, trimethoprim, kanamycin, vancomycin, rifampin, azithromycin, and clindamycin. Also, molecular detection was carried out using the PCR master mix kit (Ampliqon, Denmark), and primers (synthesized by Taq Copenhagen Co, Denmark). For cell culture experiments, reagents were obtained from DNAbiotech Co. (Iran).

\section{Sampling}

Twenty six saliva and 11 stool samples were collected from healthy human individuals. People were informed regarding the study, and written consent forms were provided. This study was approved by the ethics committee at the National Institute of Genetic engineering and Biotechnology (NIGEB, Tehran, Iran) and registered as IR.NIGEB.EC.1398.12.3.B. Samples were transported to the laboratory on ice and were immediately diluted with peptone water, spread onto de Man-Rogosa-Sharpe (MRS) agar medium and Brain Heart Infusion (BHI) agar, then incubated for $48-72 \mathrm{~h}$ at $37^{\circ} \mathrm{C}$ under aerobic and microaerophilic (by using an anaerobic jar) conditions. 


\section{Biochemical and Morphological Characterization}

Morphological characterization was carried out using the Gram staining technique, and biochemical characterization was performed using the catalase test and analysis of carbohydrate fermentation profiles. Physiological tests included the ability to grow in the presence of $\mathrm{NaCl}[3 \%$ and $4.5 \%(\mathrm{w} / \mathrm{v})]$, and also at temperatures of $15^{\circ} \mathrm{C}$ and $45^{\circ} \mathrm{C}$. All catalase-negative and Grampositive bacilli or cocci, the morphology of which was similar to LAB bacteria were classified as potential probiotic strains.

\section{Hemolytic Activity}

Fresh bacterial cultures were streaked onto blood agar media [containing 5-10\% sheep blood (Zist Royesh Co, Iran)] and incubated for $24 \mathrm{~h}$ at $37^{\circ} \mathrm{C}$. The isolates were then examined for the presence of clear zones surrounding the colonies. Clear zones are considered as beta hemolysis, greenish zones as alpha hemolysis and the absence of zones indicating no hemolysis is known as gamma hemolysis. Colonies showing beta or alpha hemolysis were excluded, and only those with gamma hemolysis were selected (Halder et al., 2017).

\section{Survival Under Low pH}

In order to determine the acid tolerance of the bacterial isolates, a procedure was carried out in accordance with standard protocols, but with some minor modifications (Vernazza et al., 2006; Haghshenas et al., 2016). Briefly, fresh overnight bacterial cells were harvested by centrifugation and inoculated at $1 \%(\mathrm{v} / \mathrm{v})$ into MRS broth ( $\mathrm{pH} 3$ ). The cultures were incubated for $3 \mathrm{~h}$ at $37^{\circ} \mathrm{C}$. Thereafter, culture samples were removed at 0 and $3 \mathrm{~h}$, and spread onto MRS agar plates, which were then incubated at $37^{\circ} \mathrm{C}$. Survival rate was measured at 0 and $3 \mathrm{~h}$ after incubation using the colony count procedure.

\section{Bile Salt Tolerance}

This test was conducted according to the method by Nami et al. (2019b), but with some minor changes. In brief, overnight bacterial cultures were inoculated at $1 \%(\mathrm{v} / \mathrm{v})$ into both MRS broth media (control) and MRS broth containing 0.3\% (w/v) oxgall (Ibresco Co, Iran). They were both incubated for $4 \mathrm{~h}$ at $37^{\circ} \mathrm{C}$, and the optical density (OD) of the cultures was then measured at $600 \mathrm{~nm}$. Subsequently, the percentage of growth inhibition was determined with the following formula:

$$
\text { Inhibition\% = }
$$

(Growth in control -Growth in oxgall/Growth in control) $\times 100$

\section{Antagonistic Activity Against Pathogens}

To detect the LAB inhibitory properties against chosen pathogens, the well diffusion assay method was used (Alkalbani et al., 2019; Chen et al., 2019). Briefly, bacterial isolates cultured at $37^{\circ} \mathrm{C}$ for $24-48 \mathrm{~h}$ were centrifuged for $10 \mathrm{~min}$ at $10,000 \mathrm{rpm}$, and the resulting supernatants were then separated and used against ten pathogenic bacterial and fungal strains including, S. aureus ATCC 25923, Salmonella enterica ATCC 14028, P. aeruginosa ATCC 27853, Methicillin-resistant Staphylococcus aureus (MRSA) ATCC 33591, Escherichia coli (E. coli) ATCC 25922, S. mutans ATCC 35668, Listeria monocytogenes ATCC 13932, Bacillus cereus ATCC 11778, Enterococcus faecalis ATCC 29212, and Candida albicans ATCC 10231. After $24 \mathrm{~h}$ of incubation, the inhibition zones around the wells were measured. Each test was conducted in triplicate.

\section{Antibiotic Susceptibility Test}

The antibiotic susceptibility test was conducted using the disk diffusion assay method. Fresh overnight cultures of bacterial isolates were spread onto MRS or BHI agar plates, and 13 antibiogram disks were then carefully placed on the agar plates, which were subsequently incubated at $37^{\circ} \mathrm{C}$ for $24 \mathrm{~h}$. The antibiotic disks consisted of gentamycin $(10 \mu \mathrm{g})$, cefixime $(5 \mu \mathrm{g})$, penicillin $(10 \mu \mathrm{g})$, chloramphenicol $(30 \mu \mathrm{g})$, streptomycin $(10 \mu \mathrm{g})$, erythromycin $(15 \mu \mathrm{g})$, ampicillin $(10 \mu \mathrm{g})$, trimethoprim (5 $\mu \mathrm{g})$, kanamycin $(30 \mu \mathrm{g})$, vancomycin $(30 \mu \mathrm{g})$, rifampin $(5 \mu \mathrm{g})$, azithromycin $(15 \mu \mathrm{g})$, and clindamycin $(2 \mu \mathrm{g})$. Finally, results were reported according to the Clinical and Laboratory Standards Institute (CLSI) guidelines (Kook et al., 2019).

\section{Adhesion Ability}

The human colon carcinoma cell line (Caco-2; kindly provided by NIGEB) was grown in high glucose Dulbecco's Modified Eagle's Medium (DMEM; DNAbiotech Co, Iran) supplemented with $10 \%$ FBS and $1 \%$ Penicillin-Streptomycin, at $37^{\circ} \mathrm{C}$ with a $5 \% \mathrm{CO}_{2}$ atmosphere. The medium was changed every other day until the cell confluency of $70-80 \%$ was reached. The cells were then trypsinized, counted $\left(4 \times 10^{5}\right.$ cells $\left./ \mathrm{mL}\right)$ and transferred to a 24-well dish. The absorbance of the freshly prepared bacterial cultures was adjusted to $0.5 \mathrm{McF}$ arland using DMEM. Then, 100 microliters of bacterial suspension were added to each well followed by incubation at $37^{\circ} \mathrm{C}$ for $2 \mathrm{~h}$. Afterward, cells were washed twice with phosphate buffer saline (PBS), fixed with methanol and stained with crystal violet for $5 \mathrm{~min}$. Adherent cell numbers were counted as outlined previously by (Fernández et al., 2003).

\section{Molecular Identification}

The bacterial isolates that fulfilled the selection criteria for probiotics were finally chosen as probiotic candidates to be identified genotypically using the $16 \mathrm{~S}$ rRNA gene amplification method.

The PCR reaction mixture with a total volume of 25 microliters, consisted of $10 \mathrm{pmol}$ primers, and the PCR master mix reaction mixture. The following universal primers; $27 \mathrm{~F}\left(5^{\prime}\right.$ AGA GTT TGA TCC TGG CTC AG $3^{\prime}$ ) and 1492R (5' GGT TAC CTT GTT ACG ACT T $3^{\prime}$ ) were used in the reaction.

PCR program in the thermal cycler (peQlab, United States) was comprised of initial denaturation at $95^{\circ} \mathrm{C}$ for $10 \mathrm{~min}$ followed by 35 cycles containing the second denaturation at $95^{\circ} \mathrm{C}$ for $1 \mathrm{~min}$, annealing at $60^{\circ} \mathrm{C}$ for $1 \mathrm{~min}$ and extension at $72^{\circ} \mathrm{C}$ for $1 \mathrm{~min}$ and $30 \mathrm{~s}$, followed by a final extension step at $72^{\circ} \mathrm{C}$ for $10 \mathrm{~min}$.

PCR products were detected and visualized by agarose gel electrophoresis $(1 \% \mathrm{w} / \mathrm{v})$ and subsequently sequenced. The resulting Sanger sequencing data were employed by the 
basic local alignment search tool (BLAST) to obtain sequence similarities. Thereafter, the sequences were registered in the $\mathrm{NCBI}^{1}$ database and assigned with accession numbers.

\section{Biofilm Production}

The potential ability of probiotic strains to form biofilm was investigated, as previously reported by Pérez Ibarreche et al. (2014). After $24 \mathrm{~h}$ of incubation at $37^{\circ} \mathrm{C}$, the $\mathrm{OD}$ of the isolates was measured at $570 \mathrm{~nm}$ using an ELISA microplate reader (Biotech, United States). Comparison of the strains with the negative control (MRS and PBS), revealed the strains competency in biofilm formation. Each test was conducted in three experiments and the final cut- off was considered as nonbiofilm formation (OD $\leq$ ODc [ODc: the OD of the control]), week biofilm formation (ODc $<\mathrm{OD} \leq 2 \times \mathrm{ODc}$ ), modest biofilm formation $(2 \times \mathrm{ODc}<\mathrm{OD} \leq 4 \times \mathrm{ODc})$, and strong Biofilm formation $(4 \times \mathrm{ODc}<\mathrm{OD}$; ODc is the optical density of the control; Borges et al., 2012).

\section{Auto-Aggregation}

The auto-aggregation test evaluates the ability of isolates to adhere to the intestine, exerting antipathogenic effects (Krausova et al., 2019). This test was performed using the method by $\mathrm{Xu}$ et al. (2009). Fresh cultures of bacterial isolates (grown for 16-18 h) were washed twice with PBS, and the optical densities of the resulting bacterial suspensions were adjusted to $0.5 \mathrm{McFarland}$ at $600 \mathrm{~nm}$. They were subsequently incubated for $2 \mathrm{~h}$ at $37^{\circ} \mathrm{C}$, thereafter the upper phase was removed, and its $\mathrm{OD}$ was measured. Finally, the auto-aggregation percentage was determined by using the following formula $(\mathrm{A} 0=$ Initial $\mathrm{OD}$, $\mathrm{At}=\mathrm{OD}$ after $2 \mathrm{~h}$ ).

$$
\text { Auto }- \text { aggregation }(\%)=(\mathrm{OD} \mathrm{A0}-\mathrm{OD} \mathrm{At} / \mathrm{A} 0) \times 100
$$

\section{Hydrophobicity}

To further assess the adhesion abilities of the probiotic isolates, the hydrophobicity of the isolates was measured using the microbial adhesion to hydrocarbons (MATH) method, as described by Vinderola et al. (2004). In short, an overnight culture of the isolates was washed twice using PBS, and their optical densities were then adjusted to $0.5-0.6$ at $600 \mathrm{~nm}$ (A0). One milliliter of xylene was added to each suspension and vortexed vigorously for $1 \mathrm{~min}$. Then the mixture was incubated at $37^{\circ} \mathrm{C}$ for $1 \mathrm{~h}$. After incubation and phase separation, the aqueous phase was carefully removed to measure its absorbance (At). Hydrophobicity percentage was calculated with the formula presented below.

$$
\text { Hydrophobicity }(\%)=(1-\text { At/A0 }) \times 100
$$

\section{MTT Assay}

The 3-(4,5-Dimethylthiazol-2-yl)-2,5-diphenyltetrazolium bromide (MTT) assay was conducted to show the cytotoxic effects of bacterial culture-free supernatants on CaCo- 2 cell lines as pointed out by (Chen et al., 2017). In short, $10^{4}$ cells were

\footnotetext{
${ }^{1}$ http://www.ncbi.nlm.nih.gov/GeneBank
}

seeded in 96 microtiter plates and were allowed to attach to the bottom of the plate. Then, different concentrations (25 and 100 microliters) of the fresh bacterial culture-free supernatants were added to each well. After 24,48 , and $72 \mathrm{~h}$ of incubation at $37^{\circ} \mathrm{C}$ with a $5 \% \mathrm{CO}_{2}$ atmosphere, MTT solution was added to each well and the resulting mixtures were incubated for another 3-4 h. The solution in every single well was then collected following the addition of 100 microliters of dimethylsulfoxide (DMSO) to each well. Finally, the OD was measured using an ELISA microplate reader at $570 \mathrm{~nm}$. Cell viability was determined according to the following formula:

$$
\text { Cell viability }(\%)=(\mathrm{OD} \text { treat } / \mathrm{OD} \text { control }) \times 100
$$

\section{Statistical Analysis}

Statistical analyses were carried out using one-way analysis of variance (ANOVA) and SPSS software version 25. Each test was performed in triplicate.

\section{RESULTS}

\section{Biochemical and Morphological Test Results}

As shown in Table $\mathbf{1}$ all the strains were Gram-positive and catalase-negative, and were able to grow in the presence of $3 \%(\mathrm{w} / \mathrm{v}), 4.5 \% \mathrm{NaCl}(\mathrm{w} / \mathrm{v})$ and at the high temperature of $45^{\circ} \mathrm{C}$, while nine strains were not able to grow at $15^{\circ} \mathrm{C}$. Sugar fermentation patterns confirmed that the rod-shaped isolates were likely to be Lactobacillus strains whereas the cocci belonged to Enterococcus genus.

\section{Hemolytic Activity Results}

In terms of hemolytic activity, three strains exhibiting hemolytic activity (beta or alpha hemolysis) were excluded, and the rest, which showed non-hemolytic activity, were used for further experiments.

\section{Survival Under Low pH Conditions Results}

Among the 185 isolates screened for low $\mathrm{pH}$ tolerance, 43 exhibited tolerance to $\mathrm{pH} 3$. The colonies of the potential acidtolerant isolates were then counted at 0 and $3 \mathrm{~h}$ after incubation in MRS agar at $\mathrm{pH}$ 3. Strains SA 135, ST 80, and SA 151 demonstrated relatively the highest rate of survival after $3 \mathrm{~h}$ of incubation. The results are shown in Table 2.

\section{Bile Salt Tolerance Results}

Following the assessment of bile salt tolerance for $4 \mathrm{~h}$, isolates ST 13, SA 151, and ST 172 were shown to be the most resistant, with growth inhibition capabilities ranging from $3.21 \pm 0.01 \%$ to $10.71 \pm 0.03 \%$, however, isolates SA 171, SA 109, and SA 179 exhibited the least resistance, ranging from $39.56 \pm 0.02 \%$ to $27.85 \pm 0.03 \%$. In general, nearly all the strains showed above the $50 \%$ tolerance ability (Figure 1). 
TABLE 1 | Results of the morphological and biochemical tests carried out for selected isolates.

\begin{tabular}{|c|c|c|c|c|c|c|c|c|c|c|c|c|c|c|}
\hline Strains & SA 151 & SA 135 & SA 171 & SA 139 & SA 109 & SA 110 & SA 12 & SA 16 & ST 80 & ST 13 & ST 67 & ST 126 & ST 172 & ST 179 \\
\hline Cell morphology & rod & rod & rod & rod & rod & rod & rod & rod & cocci & cocci & cocci & cocci & cocci & cocci \\
\hline Gram & + & + & + & + & + & + & + & + & + & + & + & + & + & + \\
\hline Catalase & - & - & - & - & - & - & - & - & - & - & - & - & - & - \\
\hline Growth in presence of $\mathrm{NaCl} 3 \%$ & + & + & + & + & + & + & + & + & + & + & + & + & + & + \\
\hline Growth in presence of $\mathrm{NaCl} 4.5 \%$ & + & + & + & + & + & + & + & + & + & + & + & + & + & + \\
\hline Growth at $15^{\circ} \mathrm{C}$ & - & - & - & - & - & - & - & - & - & + & + & + & + & + \\
\hline Growth at $45^{\circ} \mathrm{C}$ & + & + & + & + & + & + & + & + & + & + & + & + & + & + \\
\hline \multicolumn{15}{|l|}{ Carbohydrate fermentation } \\
\hline Glucose & + & + & + & + & + & + & + & + & + & + & + & + & + & + \\
\hline Galactose & + & + & + & + & + & + & + & + & + & + & + & + & + & + \\
\hline Maltose & + & + & + & + & + & + & + & + & + & + & + & + & + & + \\
\hline Mannose & - & - & - & - & - & - & - & - & - & + & + & + & + & + \\
\hline Manitol & + & + & + & + & + & + & + & + & + & + & + & + & + & - \\
\hline Cellobiose & + & + & + & + & + & + & + & + & + & + & + & + & + & + \\
\hline Rhamnose & - & - & - & - & - & - & - & - & - & - & - & - & - & - \\
\hline L-Arabinose & + & + & + & + & + & + & + & + & + & + & + & + & + & - \\
\hline Fructose & + & + & + & + & + & + & + & + & + & + & + & + & + & + \\
\hline L-xylose & + & + & + & + & + & + & + & + & + & - & - & - & - & - \\
\hline Sorbitol & + & + & + & + & + & + & + & + & + & - & - & - & - & + \\
\hline Sucrose & + & + & + & + & + & + & + & + & + & + & + & + & + & + \\
\hline Lactose & + & + & + & + & + & + & + & + & + & + & + & + & + & + \\
\hline Inositol & + & + & + & + & + & + & + & + & + & + & + & + & + & + \\
\hline
\end{tabular}

\section{Antagonicity Test Results}

The isolated strains were assessed for antimicrobial activity against ten types of pathogens. The results are indicated in Table 3. Certain isolates had an inhibitory impact on the selected pathogens. The four isolates, SA 151, SA 135, ST 80, and SA 139 were able to moderately constrain a wide array of pathogens. Seven isolates including SA 171, SA 12, SA 109, SA 110, SA 16, ST 13, and ST 126 were able to inhibit at least four types of pathogens. Six isolates

TABLE 2 | Acid tolerance and survival rate of selected isolates under acidic conditions.

\begin{tabular}{lccc}
\hline Strains & 0 h CFU/ml & 3 h CFU/ml & Survival rate (\%) \\
\hline SA 151 & $6.17 \pm 0.1$ & $6.01 \pm 0.03$ & $97.4 \%$ \\
SA 135 & $7.38 \pm 0.01$ & $7.33 \pm 0.03$ & $99.32 \%$ \\
ST 80 & $6.51 \pm 0.01$ & $6.46 \pm 0.01$ & $99.23 \%$ \\
SA 139 & $6.47 \pm 0.1$ & $6.17 \pm 0.1$ & $95.36 \%$ \\
SA 171 & $6.47 \pm 0.1$ & $5.60 \pm 0.1$ & $86.55 \%$ \\
SA 12 & $7.8 \pm 0.06$ & $7.3 \pm 0.3$ & $93.58 \%$ \\
SA 109 & $6.54 \pm 0.06$ & $5.17 \pm 0.1$ & $79.05 \%$ \\
SA 110 & $7.09 \pm 0.08$ & $5.87 \pm 0.02$ & $82.79 \%$ \\
SA 16 & $6.47 \pm 0.03$ & $5.54 \pm 0.06$ & $85.62 \%$ \\
ST 13 & $7.17 \pm 0.1$ & $6.17 \pm 0.1$ & $86.05 \%$ \\
ST 67 & $6.49 \pm 0.01$ & $6.30 \pm 0.2$ & $97.07 \%$ \\
ST 126 & $6.47 \pm 0.1$ & $5.30 \pm 0.2$ & $81.91 \%$ \\
ST 172 & $7.14 \pm 0.03$ & $5.65 \pm 0.04$ & $79.13 \%$ \\
ST 179 & $6.90 \pm 0.05$ & $5.47 \pm+0.1$ & $79.27 \%$ \\
\hline
\end{tabular}

Values are mean \pm standard deviation of triplicates.
(SA 151, SA 135, ST 80, SA 109, SA 110, and SA 16) could inhibit the MRSA even though none inhibited the S. enterica strain.

\section{Evaluation of Antibiotic Susceptibility}

As shown in Table 4, antibiotic susceptibility tests using the disk diffusion method indicated that all the strains were resistant to kanamycin and streptomycin, except for SA 109, which was sensitive to streptomycin; nevertheless, each of the isolates was sensitive to chloramphenicol and ampicillin. No antibiotic resistance patterns were reported for erythromycin and clindamycin except intermediate susceptibility in (SA 139, SA 12 , and ST 126) and (ST 80 and ST 179), respectively. Strains were resistant to gentamycin $(n=5)$, cefixime $(n=6)$, penicillin $(n=3)$, trimethoprim $(n=9)$, vancomycin $(n=8)$, rifampin $(n=6)$, and azithromycin $(n=1)$. Resistance rate, calculated via the number of antibiotic resistance of each strain to the whole number of tested antibiotics, varied from 23.07\% (represented by SA 151, ST 110, and ST 16) to $46.15 \%$ (demonstrated by SA 139 , ST 13).

\section{Adhesion Ability Results}

An essential criterion for the selection of a probiotic is the ability to adhere to mucosal surfaces and epithelial cells, to allow its survival and colonization of the human gut. Hence the adhesion ability of probiotic candidates was examined using the Caco-2 cell line. Isolates SA 135, SA 171, SA 139, SA 12, ST 126, ST 172, ST 179 , and ST 67 were able to adhere firmly to Caco-2 cell line while ST 80, SA 151, ST 109, ST 110, ST 16, and ST 13 showed moderate adhesion ability (Table 5). 


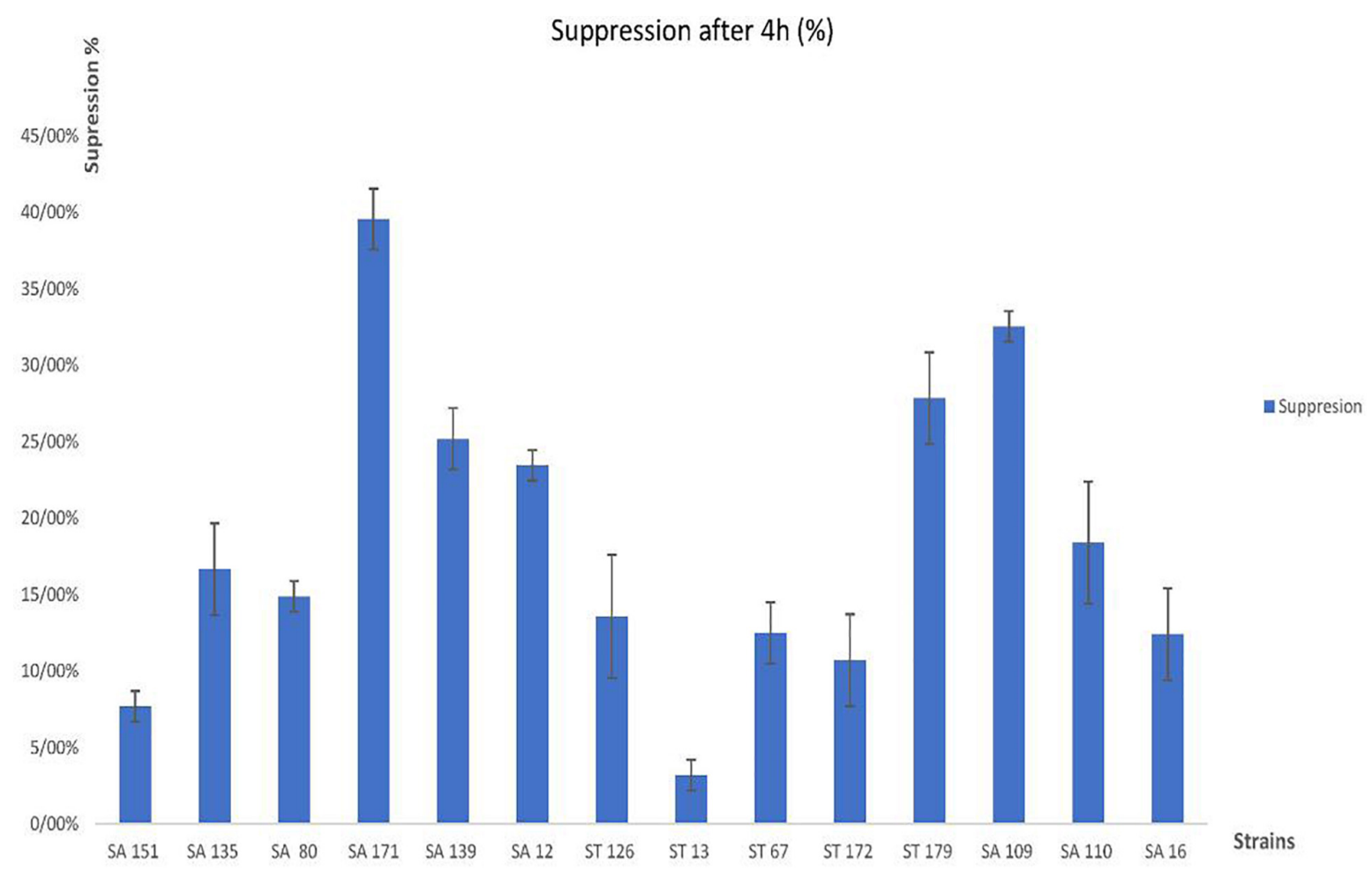

FIGURE 1 | Percentage growth inhibition (suppression) of the 14 selected isolates by bile salts.

TABLE 3 | Antimicrobial activities against ten pathogens.

\begin{tabular}{|c|c|c|c|c|c|c|c|c|c|c|}
\hline Strains & $\begin{array}{l}\text { S. aureus } \\
(\mathrm{mm})\end{array}$ & $\begin{array}{l}\text { L. monocytogenes } \\
\qquad(\mathrm{mm})\end{array}$ & $\begin{array}{l}\text { B. cereus } \\
\text { (mm) }\end{array}$ & $\begin{array}{l}\text { S. mutans } \\
(\mathrm{mm})\end{array}$ & E. coli $(\mathrm{mm})$ & $\begin{array}{l}\text { P. aeruginosa } \\
(\mathrm{mm})\end{array}$ & $\begin{array}{l}\text { C. albicans } \\
(\mathrm{mm})\end{array}$ & $\begin{array}{l}\text { E. faecalis } \\
\qquad(m m)\end{array}$ & MRSA (mm) & $\begin{array}{l}\text { S. enterica } \\
(\mathrm{mm})\end{array}$ \\
\hline SA 151 & 15 & 13 & 15 & 10.5 & - & 15.5 & 15.5 & 11 & 20 & - \\
\hline SA 135 & 15 & 15 & 16 & 15 & - & 17 & 20 & - & 11 & - \\
\hline ST 80 & 12 & 16 & 18 & 11 & - & 15 & 22 & - & 17 & - \\
\hline SA 139 & - & 10 & 13 & 15 & 10 & 13 & 16 & 10 & - & - \\
\hline SA 171 & 18 & - & 15 & 15 & - & 20 & 19 & - & - & - \\
\hline SA 110 & - & - & 10 & 10 & - & 12 & 20 & - & 25 & - \\
\hline SA 16 & - & - & 12 & 12 & - & 14 & 15 & - & 21 & - \\
\hline ST 13 & - & 14 & 10 & - & 14 & 12 & - & 10 & - & - \\
\hline ST 67 & - & 13 & 9 & - & - & - & - & 10 & - & - \\
\hline ST 126 & - & 13 & 13 & - & 15 & 17 & - & 15 & - & - \\
\hline
\end{tabular}

The zone diameter values above are the average of two experiments and presented in millimeter $(\mathrm{mm})$.

16s rRNA Sequencing and Phylogenetic Tree Results

Fourteen selected candidates were investigated for molecular characterization using the Sanger sequencing method and the BLAST tool. The Sanger sequencing data analysis and the resulting phylogenetic tree revealed that the isolates belong to L. fermentum, Enterococcus faecium, and Enterococcus hirae strains. All the isolates' names and accession numbers can be found in Table 6. The phylogenetic tree was constructed by MEGAX software using the bootstrap method (Figure 2).

\section{Biofilm Production Results}

All isolates showed strong biofilm formation except isolates SA 135 , ST 13, ST 67, and ST 126, which only showed modest biofilm production. 


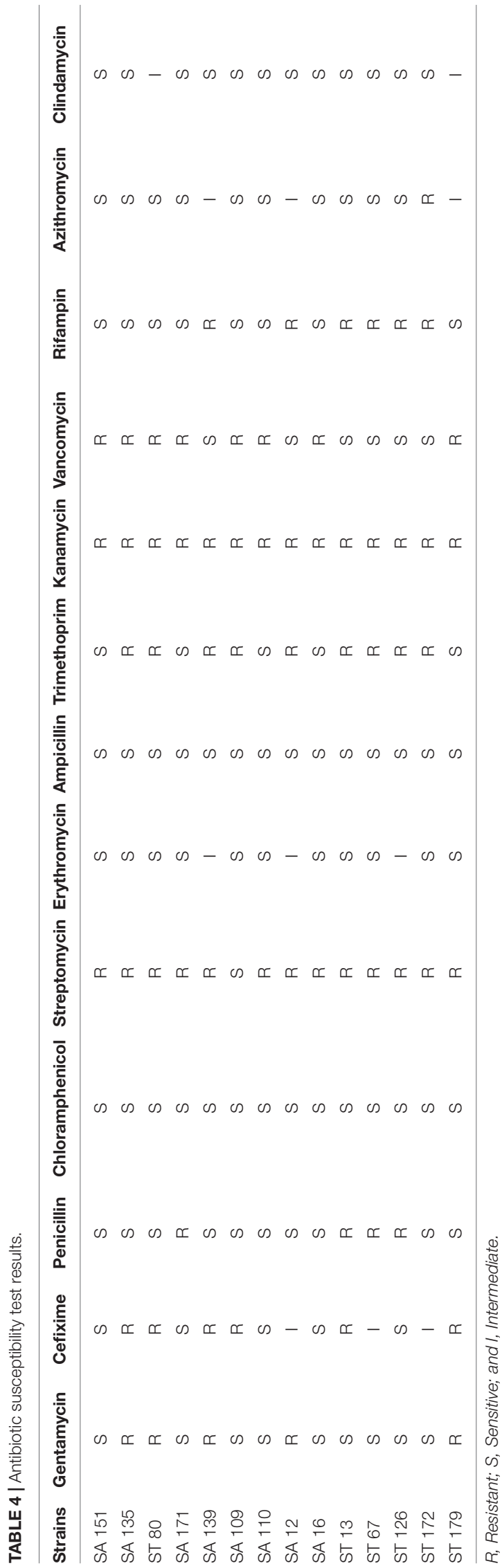

\section{Auto-Aggregation and Hydrophobicity Results}

Isolates were examined for adherence to hydrophobic surfaces, e.g., using xylene and the auto-aggregation method. As shown in Table 7, the isolates hydrophobicity extended from $0 \%$ to $69.68 \pm 0.01 \%$ while auto-aggregation ranged from $2.23 \pm 0.002 \%$ to $33.43 \pm 0.007 \%$. Maximum percentage of hydrophobicity to xylene was demonstrated by SA 135, followed by SA 151. In contrast, the highest auto-aggregation rate was observed in ST 179 and ST 13, respectively.

\section{MTT Assay Results}

The top five isolates that exhibited relatively good probiotic properties were utilized for the MTT assay on Caco-2 cell line. As shown in Figure 3, the cytotoxic activities varied from $38 \%$ to $89 \%$ at $25 \%(\mathrm{v} / \mathrm{v})$ concentration after $24 \mathrm{~h}$ of incubation, while boosting the concentration of supernatants to $100 \%$, nearly all the cells were killed during the incubation period. By increasing the incubation period and the concentration of the supernatants, cytotoxic activity had fallen to $7 \%$ in the SA 171 isolate after $72 \mathrm{~h}$ of incubation. In general, isolates SA 171, ST 80 revealed the best cytotoxicity after $24 \mathrm{~h}$ of incubation.

\section{DISCUSSION}

Over the past decades, research in probiotics has gained a surge of interest because of their multiple health benefits and market demands. Many investigations have been undertaken to isolate new promising probiotic species from the human gut and salivary microbiota (Kiliç and Karahan, 2010; Vijayabharathi et al., 2012; Terai et al., 2015), but continuous research is required due to their species-specific features.

Probiotics used by humans are usually isolated from different environments that include dairy and non-dairy sources. However, probiotics that are isolated from human or animal intestines have certain characteristics that differ from those isolated from dairy products. For example, probiotics isolated from the human gut are usually more resistant to high bile salt concentrations and low $\mathrm{pH}$ levels. Furthermore, they possess higher adhering abilities when compared to those of dairyisolated probiotics. Thus, non-diary probiotics are highly likely to be exploited in people who suffer from lactose intolerance (Sornplang and Piyadeatsoontorn, 2016; Sardana et al., 2018).

Traditional probiotics that have long been used globally, only cover a small spectrum of microorganisms. With the advent of next-generation sequencing, a greater understanding of the gut microbiome is revealing an immense number of new microorganisms with unknown characteristics that could have potential healing properties. The extensive research that is currently demonstrating the multidimensional benefits of the gut microbiome on human health will inevitably culminate in the identification and development of new microbial strains with novel therapeutic properties valuable to human health and the pharmaceutical industry. Accordingly, these new potential probiotic strains are referred to as "next-generation probiotics" (O’Toole et al., 2017). 
TABLE 5 | The adhesion ability of the selected isolates.

\begin{tabular}{lccc}
\hline Strains & Adhesion & Strains & Adhesion \\
\hline SA 135 & Strong & ST 67 & Strong \\
SA 171 & Strong & ST 80 & Moderate \\
SA 139 & Strong & SA 151 & Moderate \\
SA 12 & Strong & SA 109 & Moderate \\
ST 126 & Strong & SA 110 & Moderate \\
ST 172 & Strong & SA 16 & Moderate \\
ST 179 & Strong & ST 13 & Moderate \\
\hline
\end{tabular}

TABLE 6 | Candidate probiotics identified based on percentage similarity of the 16s rRNA sequence to those available in the GenBank database.

\begin{tabular}{lccc}
\hline Accession Number & Name & Similarity (\%) & Strains \\
\hline ST 80 & $84.44 \%$ & Enterococcus faecium & MT815471 \\
SA 151 & $90.43 \%$ & Lactobacillus fermentum & MN128866 \\
SA 135 & $98.30 \%$ & Lactobacillus fermentum & MN475882 \\
SA 12 & $98.65 \%$ & Lactobacillus fermentum & MN475960 \\
SA 139 & $98.93 \%$ & Lactobacillus fermentum & MN128688 \\
ST 13 & $98.97 \%$ & Enterococcus faecium & MN475959 \\
SA 109 & $99.00 \%$ & Lactobacillus fermentum & MN475903 \\
ST 172 & $99.04 \%$ & Enterococcus faecium & MN128647 \\
SA 171 & $99.15 \%$ & Lactobacillus fermentum & MN475879 \\
SA 110 & $99.20 \%$ & Lactobacillus fermentum & MN475967 \\
ST 179 & $99.35 \%$ & Enterococcus hirae & MN147877 \\
SA 16 & $99.43 \%$ & Lactobacillus fermentum & MN475920 \\
ST 126 & $99.71 \%$ & Enterococcus faecium & MN148088 \\
ST 67 & $99.78 \%$ & Enterococcus faecium & MN475904 \\
\hline
\end{tabular}

This study seeks new probiotic strains, hence, lactic acid bacteria were isolated from the gut and saliva of healthy human individuals. In total, 185 isolated were tested for probiotic properties.

Before approving any probiotic for its health benefits and use in the food industry, its safety must be evaluated by in vitro and in vivo studies. The two main experimental tests that are carried out in this regard are the hemolysis and antibiotic resistance tests (Oh and Jung, 2015). None of the selected strains in this study showed beta-hemolytic activity.

The ability to tolerate harsh conditions, e.g., low $\mathrm{pH}$, gastric juice, and bile salts, are the main contributing factors in the selection of good probiotic candidates (Kandylis et al., 2016). One of the key features in the selection of probiotics is acid tolerance, since they must be able to survive under the low $\mathrm{pH}$ conditions of the gastric juice in the stomach. In this study, the survival rate in acidic and bile salt circumstances vastly varied from one strain to another, suggesting a strain-specific pattern. Isolates SA 135, SA 151 , and ST 80 showed maximum survival ability in the presence of acidic and bile salt conditions. The results of this study are in agreement with those of previous research (Chou and Weimer, 1999; Zago et al., 2011).

In our study, the inhibitory effects of LAB supernatants were found against a variety of pathogens including $S$. aureus, P. aeruginosa, MRSA, E. coli, S. mutans, L. monocytogenes, B. cereus, E. faecalis, and C. albicans. Our results differ somewhat from the published studies, whereby the LAB could not affect Gram-negative pathogens (Zommiti et al., 2018). These findings emphasize the importance of the selected strains in our studies, as they tend to show broad-spectrum antimicrobial activities, particularly against antibiotic-resistant microorganisms such as MRSA and the fungus, C. albicans. Although the broad antimicrobial effects of LABs are most often the result of organic acid production, the activity of antimicrobial peptides and other metabolites that may be produced by such strains cannot be ruled out (Kivanç et al., 2011; Somashekaraiah et al., 2019).

Another significant feature of probiotics is their ability to colonize the gut, which can be evaluated by the Caco2 cell adhesion assay (Kozak et al., 2016), auto-aggregation, and hydrophobicity tests (Collado et al., 2008). In this research, the probiotic candidates showed a diverse adhesion model, demonstrating moderate to strong adhesion patterns. Regarding hydrophobicity and auto-aggregation, the highest

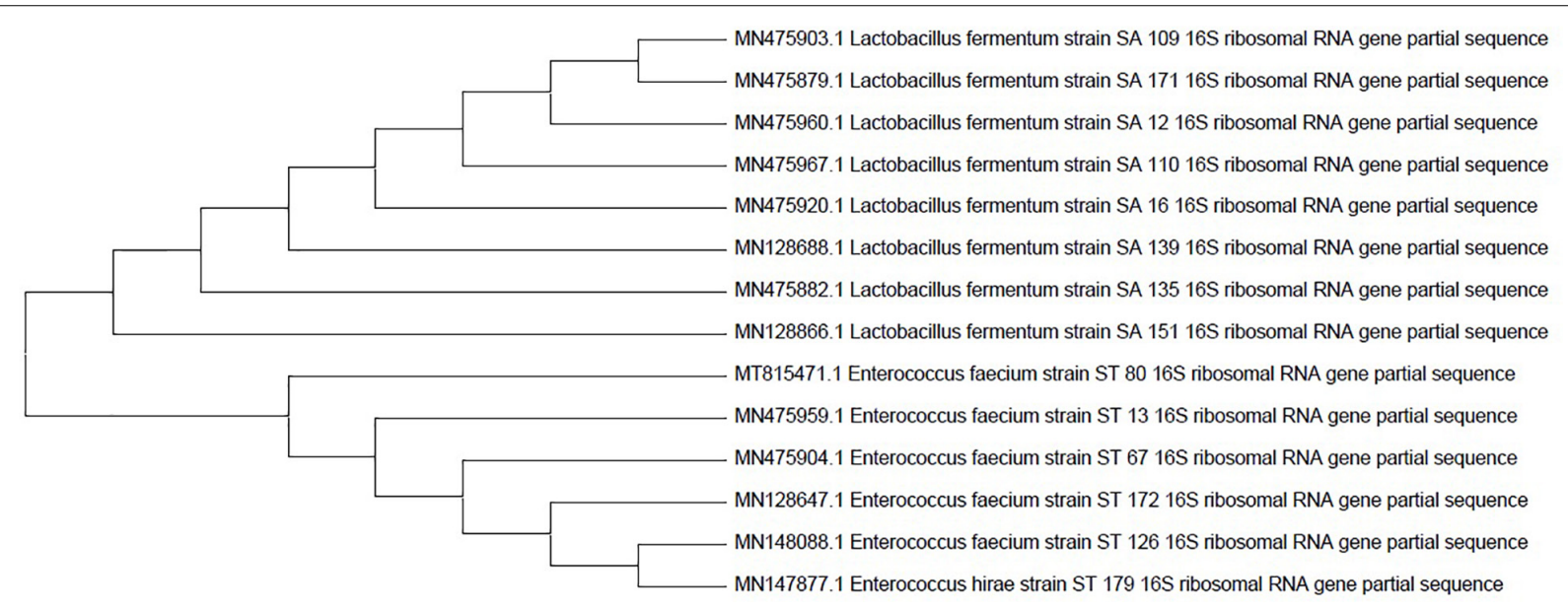

FIGURE 2 | Phylogenetic tree of the 14 probiotic isolates based on 16s rRNA sequences. The tree was constructed by the MEGAX software using the bootstrap method. 
TABLE 7 | Percentage of cell surface hydrophobicity of candidate probiotic strains.

\begin{tabular}{|c|c|c|c|c|c|}
\hline Strains & Auto-aggregation (\%) & Hydrophobicity (\%) & Strains & Auto-aggregation (\%) & Hydrophobicity (\%) \\
\hline SA 151 & $16.23 \pm 0.002$ & $55.84 \pm 0.08$ & SA 16 & $15.77 \pm 0.004$ & $27.12 \pm 0.007$ \\
\hline ST 80 & $12.89 \pm 0.002$ & $20.69 \pm 0.003$ & SA 110 & $6.29 \pm 0.002$ & $11.51 \pm 0.04$ \\
\hline SA 135 & $13.13 \pm 0.004$ & $69.68 \pm 0.01$ & ST 13 & $17.39 \pm 0.002$ & $1.45 \pm 0.01$ \\
\hline SA 12 & $7.62 \pm 0.006$ & $41.14 \pm 0.003$ & ST 172 & $11.30 \pm 0.002$ & 0 \\
\hline SA 171 & $2.23 \pm 0.002$ & $11.48 \pm 0.007$ & ST 179 & $33.43 \pm 0.007$ & $6.44 \pm 0.01$ \\
\hline SA 139 & $11.81 \pm 0.002$ & 0 & ST 67 & $13.82 \pm 0.007$ & $5.26 \pm 0.01$ \\
\hline SA 109 & $14.79 \pm 0.005$ & $32.24 \pm 0.002$ & ST 126 & $10.57 \pm 0.007$ & $3 \pm 0.01$ \\
\hline
\end{tabular}

Values are shown in mean \pm Standard deviation.

\section{Different incubation times and concentrations}

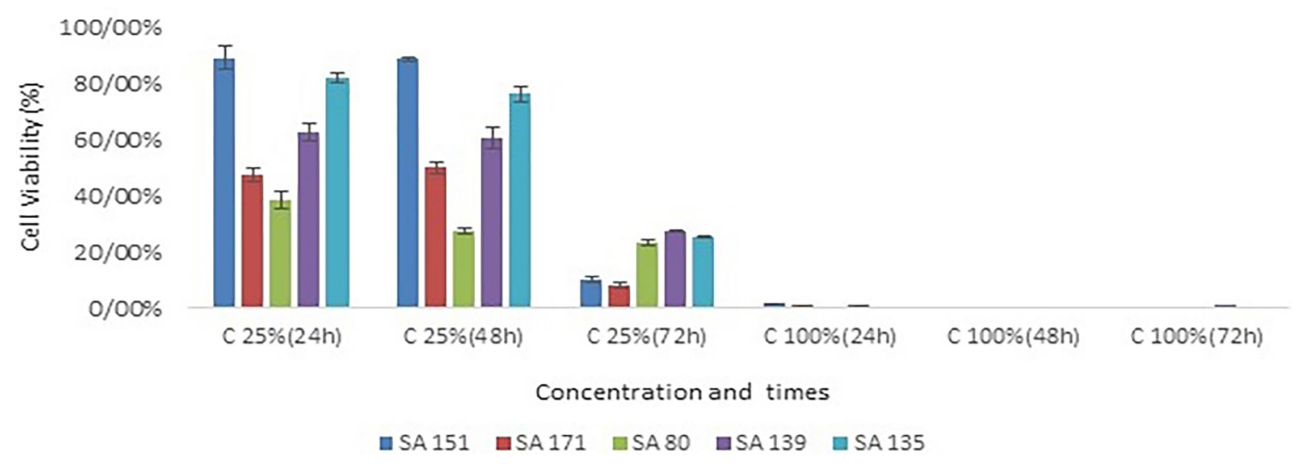

FIGURE 3 | The cytotoxic effects of bacterial culture free supernatants on the CaCo-2 cell line at different supernatant concentrations and incubation periods. The five probiotic candidates that were assessed included SA 151, SA 171, SA139 and SA 135.

rate of hydrophobicity and auto-aggregation were observed in SA 151, SA 135, and in ST 179, ST 13, respectively. The adhesion results demonstrate the ability of the selected strains to adhere to the epithelial cells and thus colonize the gut. Adhesion is a very important trait of a suitable and prevailing probiotic, as it prevents the colonization of the gastrointestinal tract by pathogenic bacteria (Abushelaibi et al., 2017; Somashekaraiah et al., 2019).

As a key feature, a good probiotic candidate should not possess or acquire any antibiotic resistance genes. Consistent with the literature, this research found that nearly all isolates were resistant to kanamycin and streptomycin, except for SA 109, which showed sensitivity to streptomycin (Kook et al., 2019). A possible explanation for these results may be the overuse of antibiotics in Iran. Notably, some were also found to be resistant to vancomycin, which is in accordance with previous reports that have shown vancomycin resistance as an intrinsic trait of LAB, such as Lactobacillus, Leuconostoc, and Pediococcus. In fact, many Lactobacillus strains, including L. fermentum are routinely used in the food industry. Vancomycin resistance in this group of bacteria is chromosomally encoded and is non-transferable and non-inducible (Swenson et al., 1990; Tynkkynen et al., 1998; Sharma et al., 2014).

Another important characteristic of the potential probiotic candidates in this study is their anti-cancer properties. Five of the selected isolates demonstrated antiproliferative activities against the human colon cancer cell line (Caco-2). Their culture supernatants inhibited the growth of cancerous cells by up to $7 \%$ after $72 \mathrm{~h}$ of incubation at the concentration of $25 \%$. Our study confirms a previous finding by Lee et al. (2019), who demonstrated the antiproliferative effects of the culture-free supernatant (CFS) of a L. fermentum strain against colorectal cancer (CRC). It was shown that the CFS induces apoptosis, thereby inhibiting cell growth in CRC lines. The antiproliferative activity of $L$. fermentum is brought about by preventing NF- $\mathrm{B}$ signaling. They showed that the Lactobacillus CFS is capable of inducing cell death, and thus has the potential to be used as a powerful multitarget anti-cancer chemotherapeutic agent (Lee et al., 2019).

In a previous study by Wei et al. (2019), it was suggested that exopolysaccharide (EPS) extracted from L. fermentum YL-11 could inhibit Caco-2 and HT-29 cell lines by up to $45.6 \pm 6.1 \%$. They proved that EPS could act as an antiproliferative agent in these two types of CRC cell lines (Wei et al., 2019).

Overall, we were able to select 14 potential probiotics with multifaceted probiotic attributes. These strains were subsequently characterized and identified genotypically, and were found to belong to the Lactobacillus and Enterococcus genus. By considering the unique characteristics of these indigenous probiotic strains, they can be of great benefit to the pharmaceutical, cosmetic, and food industries. Furthermore, this study also proved that the human gut and saliva can act as suitable sources of novel probiotics with desirable functional properties. 


\section{CONCLUSION}

Given the favorable probiotic attributes in our isolates, the following conclusion can be drawn that saliva and feces are two suitable and potential sources for isolating novel probiotics strains of human origin. Since the isolates of this study, in particular SA 151, ST 80, and SA 135, showed relatively good antipathogenic activity, survival in harsh conditions, biofilm production, and reasonable adhesion, they could, therefore, be viewed as promising "next generation" probiotic candidates, useful to the pharmaceutical industry.

\section{DATA AVAILABILITY STATEMENT}

The datasets presented in this study can be found in online repositories. The names of the repository/repositories and accession number(s) can be found in the article/ supplementary material.

\section{ETHICS STATEMENT}

The study involving human participants was reviewed and approved by the Ethics Committee at the National Institute of Genetic engineering and Biotechnology (NIGEB, Tehran, Iran), and was registered as IR.NIGEB.EC.1398.12.3.B. The

\section{REFERENCES}

Abushelaibi, A., Al-Mahadin, S., El-Tarabily, K., Shah, N. P., and Ayyash, M. (2017). Characterization of potential probiotic lactic acid bacteria isolated from camel milk. LWT Food Sci. Technol. 79, 316-325. doi: 10.1016/j.lwt.2017.01.041

Alkalbani, N. S., Turner, M. S., and Ayyash, M. M. (2019). Isolation, identification, and potential probiotic characterization of isolated lactic acid bacteria and in vitro investigation of the cytotoxicity, antioxidant, and antidiabetic activities in fermented sausage. Microb. Cell Fact 18:188. doi: 10.1186/s12934-0191239-1

Anwar, F., Altayb, H. N., Al-Abbasi, F. A., Al-Malki, A. L., Kamal, M. A., and Kumar, V. (2020). Antiviral effects of probiotic metabolites on COVID-19. J. Biomol. Struct. Dyn. 1-10. doi: 10.1080/07391102.2020.1775123

Besser, M., Terberger, J., Weber, L., Ghebremedhin, B., Naumova, E. A., Arnold, W. H., et al. (2019). Impact of probiotics on pathogen survival in an innovative human plasma biofilm model (hpBIOM). J. Transl. Med. 17:243. doi: 10.1186/ s12967-019-1990-4

Borges, S., Silva, J., and Teixeira, P. (2012). Survival and biofilm formation by Group B Streptococci in simulated vaginal fluid at different pHs. Antonie Van Leeuwenhoek Int. J. Gen. Mol. Microbiol. 101, 677-682. doi: 10.1007/s10482011-9666-y

Chen, C. C., Lai, C. C., Huang, H. L., Huang, W. Y., Toh, H. S., Weng, T. C., et al. (2019). Antimicrobial activity of Lactobacillus species against carbapenemresistant Enterobacteriaceae. Front. Microbiol. 10:789. doi: 10.3389/fmicb.2019. 00789

Chen, Z. Y., Hsieh, Y. M., Huang, C. C., and Tsai, C. C. (2017). Inhibitory effects of probiotic Lactobacillus on the growth of human colonic carcinoma cell line HT-29. Molecules 22:107. doi: 10.3390/molecules22010107

Chou, L. S., and Weimer, B. (1999). Isolation and characterization of acid- and biletolerant isolates from strains of Lactobacillus acidophilus. J. Dairy Sci. 82, 23-31. doi: 10.3168/jds.S0022-0302(99)75204-5 patients/participants provided their written informed consent to participate in this study.

\section{AUTHOR CONTRIBUTIONS}

PS contributed to the original idea, conceptualization, supervision and project administration. HB and PS contributed to the design, methodology and implementation of research. PS and $\mathrm{HB}$ contributed to the writing and original draft preparation of the manuscript. PS contributed to the full revision and editing of the manuscript. $\mathrm{HB}, \mathrm{PS}, \mathrm{SAJ}, \mathrm{AA}$, and $\mathrm{MB}$ contributed to the analysis of the results and to the writing and editing of the manuscript.

\section{FUNDING}

This work was financially supported by the National Institute of Genetic Engineering and Biotechnology (NIGEB).

\section{ACKNOWLEDGMENTS}

We would like to thank the National Institute of Genetic Engineering and Biotechnology (NIGEB) for financial assistance and provision of facilities. We also thank all the volunteers who participated in this study and those who have helped us during this study.

Collado, M. C., Meriluoto, J., and Salminen, S. (2008). Adhesion and aggregation properties of probiotic and pathogen strains. Eur. Food Res. Technol. 226, 1065-1073. doi: 10.1007/s00217-007-0632-x

Daliri, E. B. M., Lee, B. H., and Oh, D. H. (2017). Current perspectives on antihypertensive probiotics. Probiot. Antimicrob. Proteins 9, 91-101. doi: 10. 1007/s12602-016-9241-y

Dargahi, N., Johnson, G., and Apostolopoulos, V. (2020). Streptococcus thermophilus alters the expression of genes associated with innate and adaptive immunity in human peripheral blood mononuclear cells. PLoS One 15:e0228531. doi: 10.1371/journal.pone.0228531

d'Ettorre, G., Ceccarelli, G., Marazzato, M., Campagna, G., Pinacchio, C., Alessandri, F., et al. (2020). Challenges in the management of SARS-CoV2 infection: the role of oral bacteriotherapy as complementary therapeutic strategy to avoid the progression of COVID-19. Front. Med. 7:389. doi: 10.3389/ fmed.2020.00389

Drago, L. (2019). Probiotics and colon cancer. Microorganisms 7:66. doi: 10.3390/ microorganisms 7030066

Ettinger, G., MacDonald, K., Reid, G., and Burton, J. P. (2014). The influence of the human microbiome and probiotics on cardiovascular health. Gut Microb. 5, 719-728. doi: 10.4161/19490976.2014.983775

FAO/WHO (2002). Guidelines for the Evaluation of Probiotics in Food. Rome: FAO.

Fernández, M. F., Boris, S., and Barbés, C. (2003). Probiotic properties of human Lactobacilli strains to be used in the gastrointestinal tract. J. Appl. Microbiol. 94, 449-455. doi: 10.1046/j.1365-2672.2003.01850.x

Fijan, S. (2016). "Antimicrobial effect of probiotics against common pathogens," in Probiotics and Prebiotics in Human Nutrition and Health, eds V. Rao and L. G. Rao (London: InTechopen), doi: 10.5772/63141

Ganapathy, V., Thangaraju, M., Prasad, P. D., Martin, P. M., and Singh, N. (2013). Transporters and receptors for short-chain fatty acids as the molecular link between colonic bacteria and the host. Curr. Opin. Pharmacol. 13, 869-874. doi: 10.1016/j.coph.2013.08.006 
Gao, C., Ganesh, B. P., Shi, Z., Shah, R. R., Fultz, R., Major, A., et al. (2017). Gut microbe-mediated suppression of inflammation-associated colon carcinogenesis by luminal histamine production. Am. J. Pathol. 187, 2323-2336. doi: 10.1016/j.ajpath.2017.06.011

Gill, H. S., Rutherfurd, K. J., Prasad, J., and Gopal, P. K. (2000). Enhancement of natural and acquired immunity by Lactobacillus rhamnosus (HN001), Lactobacillus acidophilus (HN017) and Bifidobacterium lactis (HN019). Br. J. Nutr. 83, 167-176. doi: 10.1017/s0007114500000210

Gómez-Guzmán, M., Toral, M., Romero, M., Jiménez, R., Galindo, P., Sánchez, M., et al. (2015). Antihypertensive effects of probiotics Lactobacillus strains in spontaneously hypertensive rats. Mol. Nutr. Food Res. 59, 2326-2336. doi: 10.1002/mnfr.201500290

Haghshenas, B., Haghshenas, M., Nami, Y., Khosroushahi, A. Y., Abdullah, N., Barzegari, A., et al. (2016). Probiotic assessment of Lactobacillus plantarum $15 \mathrm{HN}$ and Enterococcus mundtii $50 \mathrm{H}$ isolated from traditional dairies microbiota. Adv. Pharm. Bull. 6:37. doi: 10.15171/APB.2016.007

Haghshenas, B., Nami, Y., Abdullah, N., Radiah, D., Rosli, R., and Khosroushahi, A. Y. (2014). Anti-proliferative effects of Enterococcus strains isolated from fermented dairy products on different cancer cell lines. J. Funct. Foods 11, 363-374. doi: 10.1016/j.jff.2014.10.002

Halder, D., Mandal, M., Chatterjee, S. S., Pal, N. K., and Mandal, S. (2017). Indigenous probiotic Lactobacillus isolates presenting antibiotic like activity against human pathogenic bacteria. Biomedicines 5:31. doi: 10.3390/ biomedicines5020031

Kahouli, I., Malhotra, M., Westfall, S., Alaoui-Jamali, M. A., and Prakash, S. (2017). Design and validation of an orally administrated active L. fermentumL. acidophilus probiotic formulation using colorectal cancer Apc $\mathrm{Min} /+$ mouse model. Appl. Microbiol. Biotechnol. 101, 1999-2019. doi: 10.1007/s00253-0167885- $\mathrm{X}$

Kandylis, P., Pissaridi, K., Bekatorou, A., Kanellaki, M., and Koutinas, A. A. (2016). Dairy and non-dairy probiotic beverages. Curr. Opin. Food Sci. 7, 58-63. doi: 10.1016/j.cofs.2015.11.012

Kang, M.-S., Lim, H.-S., Oh, J.-S., Lim, Y.-J., Wuertz-Kozak, K., Harro, J. M., et al. (2017). Antimicrobial activity of Lactobacillus salivarius and Lactobacillus fermentum against Staphylococcus aureus. Pathog. Dis. 75:ftx009. doi: 10.1093/ femspd/ftx009

Kiliç, G. B., and Karahan, A. G. (2010). Identification of lactic acid bacteria isolated from the fecal samples of healthy humans and patients with dyspepsia, and determination of their $\mathrm{pH}$, bile, and antibiotic tolerance properties. J. Mol. Microbiol. Biotechnol. 18, 220-229. doi: 10.1159/000319597

Kivanç, M., Yilmaz, M., and Çakir, E. (2011). Isolation and identification of lactic acid bacteria from boza, and their microbial activity against several reporter strains. Turkish J. Biol. 35, 313-324. doi: 10.3906/biy-0906-67

Kocsis, T., Molnár, B., Németh, D., Hegyi, P., Szakács, Z., Bálint, A., et al. (2020). Probiotics have beneficial metabolic effects in patients with type 2 diabetes mellitus: a meta-analysis of randomized clinical trials. Sci. Rep. 10:11787. doi: 10.1038/s41598-020-68440- 1

Kook, S.-Y., Chung, E.-C., Lee, Y., Lee, D. W., and Kim, S. (2019). Isolation and characterization of five novel probiotic strains from Korean infant and children faeces. PLoS One 14:e0223913. doi: 10.1371/journal.pone.0223913

Kozak, K., Charbonneau, D., Sanozky-Dawes, R., and Klaenhammer, T. (2016). Characterization of bacterial isolates from the microbiota of mothers' breast milk and their infants. Gut Microb. 6, 341-351. doi: 10.1080/19490976.2015. 1103425

Krausova, G., Hyrslova, I., and Hynstova, I. (2019). In Vitro evaluation of adhesion capacity, hydrophobicity, and auto-aggregation of newly isolated potential probiotic strains. Fermentation 5:100. doi: 10.3390/fermentation5040100

Kumar, M., Dhaka, P., Vijay, D., Vergis, J., Mohan, V., Kumar, A., et al. (2016). Antimicrobial effects of Lactobacillus plantarum and Lactobacillus acidophilus against multidrug-resistant enteroaggregative Escherichia coli. Int. J. Antimicrob. Agents 48, 265-270. doi: 10.1016/j.ijantimicag.2016.05.014

Kumar, R., Sood, U., Gupta, V., Singh, M., Scaria, J., and Lal, R. (2020). Recent advancements in the development of modern probiotics for restoring human gut microbiome Dysbiosis. Indian J. Microbiol. 60, 12-25. doi: 10.1007/s12088019-00808-y

Lee, J.-E., Lee, J., Kim, J. H., Cho, N., Lee, S. H., Park, S. B., et al. (2019). Characterization of the anti-cancer activity of the probiotic bacterium
Lactobacillus fermentum using 2D vs. 3D culture in colorectal cancer cells. Biomolecules 9:557. doi: 10.3390/biom9100557

McFarland, L. (2015). Probiotics for the primary and secondary prevention of C. difficile infections: a meta-analysis and systematic review. Antibiotics 4, 160-178. doi: 10.3390/antibiotics4020160

Nami, Y., Haghshenas, B., Haghshenas, M., Abdullah, N., and Khosroushahi, A. Y. (2015). The Prophylactic effect of probiotic Enterococcus lactis IW5 against different human cancer cells. Front. Microbiol. 6:1317. doi: 10.3389/fmicb.2015. 01317

Nami, Y., Vaseghi Bakhshayesh, R., Manafi, M., and Hejazi, M. A. (2019a). Hypocholesterolaemic activity of a novel autochthonous potential probiotic Lactobacillus plantarum YS5 isolated from yogurt. LWT Food Sci. Technol. 111, 876-882. doi: 10.1016/j.lwt.2019.05.057

Nami, Y., Vaseghi Bakhshayesh, R., Mohammadzadeh Jalaly, H., Lotfi, H., Eslami, S., and Hejazi, M. A. (2019b). Probiotic properties of Enterococcus isolated from artisanal dairy products. Front. Microbiol. 10:300. doi: 10.3389/fmicb. 2019.00300

Oh, Y. J., and Jung, D. S. (2015). Evaluation of probiotic properties of Lactobacillus and Pediococcus strains isolated from omegisool, a traditionally fermented milletalcoholic beverage in Korea. LWT Food Sci. Technol. 63, 437-444. doi: 10.1016/j.lwt.2015.03.005

O’Toole, P. W., Marchesi, J. R., and Hill, C. (2017). Next-generation probiotics: the spectrum from probiotics to live biotherapeutics. Nat. Microbiol. 2:17057. doi: 10.1038/nmicrobiol.2017.57

Pérez Ibarreche, M., Castellano, P., and Vignolo, G. (2014). Evaluation of antiListeria meat borne Lactobacillus for biofilm formation on selected abiotic surfaces. Meat Sci. 96, 295-303. doi: 10.1016/j.meatsci.2013.07.010

Plaza-Díaz, J., Ruiz-Ojeda, F. J., Vilchez-Padial, L. M., and Gil, A. (2017). Evidence of the anti-inflammatory effects of probiotics and synbiotics in intestinal chronic diseases. Nutrients 9:555. doi: 10.3390/nu9060555

Sanders, M. E. (2008). Probiotics: definition, sources, selection, and uses. Clin. Infect. Dis. 46, S58-S61. doi: 10.1086/523341

Sardana, R. K., Chhikara, N., Tanwa, B., and Pangh, A. (2018). Dietary impact on esophageal cancer in humans: a review. Food Funct. 9, 1967-1977. doi: $10.1039 / \mathrm{c} 7$ fo01908d

Sharma, P., Tomar, S. K., Goswami, P., Sangwan, V., and Singh, R. (2014). Antibiotic resistance among commercially available probiotics. Food Res. Int. 57, 176-195. doi: 10.1016/j.foodres.2014.01.025

Silva, D. R., Sardi, J. C. O., de Pitangui, N. S., Roque, S. M., da Silva, A. C. B., and Rosalen, P. L. (2020). Probiotics as an alternative antimicrobial therapy: current reality and future directions. J. Funct. Foods 73:104080. doi: 10.1016/j.jff.2020. 104080

Singh, N., Gurav, A., Sivaprakasam, S., Brady, E., Padia, R., Shi, H., et al. (2014). Activation of Gpr109a, receptor for niacin and the commensal metabolite butyrate, suppresses colonic inflammation and carcinogenesis. Immunity 40 , 128-139. doi: 10.1016/j.immuni.2013.12.007

Somashekaraiah, R., Shruthi, B., Deepthi, B. V., and Sreenivasa, M. Y. (2019). Probiotic properties of lactic acid bacteria isolated from neera: a naturally fermenting coconut palm nectar. Front. Microbiol. 10:1382. doi: 10.3389/fmicb. 2019.01382

Sornplang, P., and Piyadeatsoontorn, S. (2016). Probiotic isolates from unconventional sources: a review. J. Anim. Sci. Technol. 58:26. doi: 10.1186/ s40781-016-0108-2

Swenson, J. M., Facklam, R. R., and Thornsberry, C. (1990). Antimicrobial susceptibility of vancomycin-resistant Leuconostoc, Pediococcus, and Lactobacillus species. Antimicrob. Agents Chemother. 34, 543-549. doi: 10.1128/AAC.34.4.543

Tan, G. S. E., Tay, H. L., Tan, S. H., Lee, T. H., Ng, T. M., and Lye, D. C. (2020). Gut microbiota modulation: implications for infection control and antimicrobial stewardship. Adv. Ther. 37, 4054-4067. doi: 10.1007/s12325-020-01458-z

Terai, T., Okumura, T., Imai, S., Nakao, M., Yamaji, K., Ito, M., et al. (2015). Screening of probiotic candidates in human oral bacteria for the prevention of dental disease. PLoS One 10:e0128657. doi: 10.1371/journal.pone.0128657

Tynkkynen, S., Singh, K. V., and Varmanen, P. (1998). Vancomycin resistance factor of Lactobacillus rhamnosus GG in relation to enterococcal vancomycin resistance (van) genes. Int. J. Food Microbiol. 41, 195-204. doi: 10.1016/S01681605(98)00051-8 
Valdéz, J. C., Peral, M. C., Rachid, M., Santana, M., and Perdigón, G. (2005). Interference of Lactobacillus plantarum with Pseudomonas aeruginosa in vitro and in infected burns: the potential use of probiotics in wound treatment. Clin. Microbiol. Infect. 11, 472-479. doi: 10.1111/j.1469-0691.2005.01142.x

Vernazza, C. L., Gibson, G. R., and Rastall, R. A. (2006). Carbohydrate preference, acid tolerance and bile tolerance in five strains of Bifidobacterium. J. Appl. Microbiol. 100, 846-853. doi: 10.1111/j.1365-2672.2006. 02832.x

Vijayabharathi, R., Palanisamy, B. D., Manoharan, R. K., Sathyabama, S., Bruntha, P., and Priyadarisini, V. B. (2012). Screening for probiotic properties of strains isolated from feces of various human groups. Artic. J. Microbiol. 50, 603-612. doi: 10.1007/s12275-012-2045-1

Vinderola, C. G., Medici, M., and Perdigón, G. (2004). Relationship between interaction sites in the gut, hydrophobicity, mucosal immunomodulating capacities and cell wall protein profiles in indigenous and exogenous bacteria. J. Appl. Microbiol. 96, 230-243. doi: 10.1046/j.1365-2672.2004.02158.x

Wei, Y., Li, F., Li, L., Huang, L., and Li, Q. (2019). Genetic and biochemical characterization of an exopolysaccharide with in vitro antitumoral activity produced by Lactobacillus fermentum YL-11. Front. Microbiol. 10:2898. doi: 10.3389/fmicb.2019.02898

Westfall, S., Lomis, N., Kahouli, I., Dia, S. Y., Singh, S. P., and Prakash, S. (2017). Microbiome, probiotics and neurodegenerative diseases: deciphering the gut brain axis. Cell. Mol. Life Sci. 74, 3769-3787. doi: 10.1007/s00018-017-2550-9
Xu, H., Jeong, H. S., Lee, H. Y., and Ahn, J. (2009). Assessment of cell surface properties and adhesion potential of selected probiotic strains. Lett. Appl. Microbiol. 49, 434-442. doi: 10.1111/j.1472-765X.2009.02684.x

Zago, M., Fornasari, M. E., Carminati, D., Burns, P., Suàrez, V., Vinderola, G., et al. (2011). Characterization and probiotic potential of Lactobacillus plantarum strains isolated from cheeses. Food Microbiol. 28, 1033-1040. doi: 10.1016/j.fm. 2011.02.009

Zommiti, M., Cambronel, M., Maillot, O., Barreau, M., Sebei, K., Feuilloley, M., et al. (2018). Evaluation of probiotic properties and safety of Enterococcus faecium isolated from artisanal Tunisian Meat "Dried Ossban.". Front. Microbiol. 9:1685. doi: 10.3389/fmicb.2018.01685

Conflict of Interest: The authors declare that the research was conducted in the absence of any commercial or financial relationships that could be construed as a potential conflict of interest.

Copyright (C) 2020 Bazireh, Shariati, Azimzadeh Jamalkandi, Ahmadi and Boroumand. This is an open-access article distributed under the terms of the Creative Commons Attribution License (CC BY). The use, distribution or reproduction in other forums is permitted, provided the original author(s) and the copyright owner(s) are credited and that the original publication in this journal is cited, in accordance with accepted academic practice. No use, distribution or reproduction is permitted which does not comply with these terms. 